\title{
Evaluation of a rate-adjusted area under the curve method to reduce the impact of variability in bioequivalence testing
}

\author{
Adam Lucas ${ }^{1}$, Kayode Ogungbenro ${ }^{2}$, Shuying Yang ${ }^{3}$, Leon Aarons ${ }^{4}$, and Chao Chen ${ }^{5}$ \\ ${ }^{1}$ Evotec UK Ltd \\ ${ }^{2}$ University of Manchester \\ ${ }^{3}$ GlaxoSmithKline \\ ${ }^{4}$ University of Manchester, UK \\ ${ }^{5}$ GSK
}

November 13, 2020

\begin{abstract}
Aim: To quantify the utility of the rate-adjusted area under the concentration curve method in increasing the probability of a correct and conclusive outcome of a bioequivalence (BE) trial for highly variable drugs when clearance (CL) varies more than volume of distribution (V). Methods. Data from a large population of subjects were generated with variability in CL and V parameters and used to simulate a two-period, crossover BE trial. The $90 \%$ confidence interval for formulation comparison was determined following BE assessment using the area under the concentration curve (AUC) ratio test, and the proposed rate-adjusted AUC ratio method. An outcome of bioequivalent, non-bioequivalent or inconclusive was then assigned in relation to predefined BE limits. Results: We illustrate the utility of the rate-adjusted AUC method for BE testing when CL varies more than V. The approach is expected to enhance the probability of correctly assigning BE or non-BE and to increase study power to further reduce the risk of an inconclusive trial. Conclusions: The rate-adjusted AUC method represents a simple and readily applicable approach to enhance the BE assessment of drug products when CL varies more than $\mathrm{V}$.
\end{abstract}

\section{Hosted file}

AUC_ke_Publication_upload.pdf available at https ://authorea.com/users/375475/articles/492705evaluation-of-a-rate-adjusted-area-under-the-curve-method-to-reduce-the-impact-ofvariability-in-bioequivalence-testing

\section{Hosted file}

Figure 1.pdf available at https://authorea.com/users/375475/articles/492705-evaluationof-a-rate-adjusted-area-under-the-curve-method-to-reduce-the-impact-of-variability-inbioequivalence-testing

\section{Hosted file}

Figure 2.pdf available at https://authorea.com/users/375475/articles/492705-evaluationof-a-rate-adjusted-area-under-the-curve-method-to-reduce-the-impact-of-variability-inbioequivalence-testing

\section{Hosted file}

Figure 3.pdf available at https://authorea.com/users/375475/articles/492705-evaluationof-a-rate-adjusted-area-under-the-curve-method-to-reduce-the-impact-of-variability-inbioequivalence-testing 


\section{Hosted file}

Figure 4.pdf available at https://authorea.com/users/375475/articles/492705-evaluationof-a-rate-adjusted-area-under-the-curve-method-to-reduce-the-impact-of-variability-inbioequivalence-testing 